\title{
Prevalence and Risk Factors of Irritable Bowel Syndrome in Healthy Screenee Undergoing Colonoscopy and Laboratory Tests
}

\author{
Su Youn Nam, M.D., Ph.D. ${ }^{1 *}$, Byung Chang Kim, M.D. ${ }^{1,2}$, Kum Hei Ryu, M.D. ${ }^{1}$, and Bum Joon Park, M.D. ${ }^{1}$ \\ ${ }^{1}$ Center for Cancer Prevention \& Detection, ${ }^{2}$ Center for Colon Cancer, National Cancer Center, Gyeonggi-do, Korea
}

\section{Introduction}

The prevalence of irritable bowel syndrome (IBS) after excluding organic disease has not been reported in Korea.

\section{Methods}

Of 5,605 participants in a health screening program, inclusion criteria were persons who underwent colonoscopy and completed questionnaires. Exclusion criteria were persons diagnosed with colon cancer, inflammatory bowel disease, previous colectomy, and abnormal results of thyroid function tests. IBS was defined by Rome III criteria. Physical and psychological stress was evaluated with visual analogue scales, ranging from 0 to 10. Risk factors for IBS were estimated with odds ratios (OR) and $95 \%$ confidence intervals (Cl) using logistic regression analysis.

\section{Results}

The prevalence of IBS was $8.2 \%(5,605)$ in the total population and $9.1 \%(393 / 4,296)$ in the final study sample. IBS had a positive association with female sex (adjusted OR, 1.33; 95\% Cl, 1.00-1.79; $\mathrm{p}=0.05$ ) and current smoking (adjusted OR, 1.31; $95 \% \mathrm{Cl}_{1} 1.00-1.71 ; p=0.05$ ). The prevalence of IBS increased with increased psychological stress (adjusted $p$ for trend $=$ 0.005 ) and decreased with increasing age (adjusted $p$ for trend $<0.001)$, with adjusted OR of $0.95(95 \% \mathrm{Cl}, 0.68-1.33)$ for age of 40.0 to 49.9 years; $0.79(95 \% \mathrm{Cl}, 0.54-1.15)$ for age of 50.0 to 59.9 years; and 0.51 ( $95 \% \mathrm{Cl}, 0.30-0.86)$ for age of 60 years or more, compared with age less than 40 years. Drinking status, body mass index, hypertension, diabetes, and use of sedatives had no association with IBS.

\section{Conclusions}

The prevalence of IBS increased with decreasing age and increasing psychological stress, and was positively associated with female sex and current smoking.

\section{(J Neurogastroenterol Motil 2010;16:47-51)}

\section{Key Words}

Irritable bowel syndrome, Colonoscopy, Prevalence, Risk factors

Received: October 8th, 2009 Accepted: November 28th, 2009

(c) This is an Open Access article distributed under the terms of the Creative Commons Attribution Non-Commercial License (http://creativecommons. org/licenses/by-nc/3.0) which permits unrestricted non-commercial use, distribution, and reproduction in any medium, provided the original work is properly cited.

*Correspondence: Su Youn Nam, M.D., Ph.D.

Center for Cancer Prevention and Detection, National Cancer Center, 809 Madu 1-dong, Ilsandong-gu, Goyang, Gyeonggi-do 411-769, Korea

Tel: +82-31-920-1608, Fax: +82-31-920-0451, E-mail: mascha@ncc.re.kr

Financial support: None.

Conflicts of interest: None. 


\section{Introduction}

Irritable bowel syndrome (IBS) is a chronic, relapsing gastrointestinal problem, characterized by abdominal pain, bloating, and changes in bowel habits. Although the precise prevalence and incidence depends on the criteria used, most studies agree that it is a common disorder, and patients present frequently to general practitioners and to specialists. ${ }^{1,2}$ The prevalence of IBS is approximately $10 \%$ in Western populations ${ }^{2,3}$ and $2.6 \%$ to $9.6 \%$ in Korean populations. ${ }^{4-6}$ However, previous population-based studies did not exclude organic bowel disease using colonoscopy. ${ }^{1,2,4-6}$ Therefore, we excluded organic bowel disease using colonoscopy and abnormal laboratory tests in participants in a health screening program, and we evaluated for risk factors of IBS after adjusting for many potential confounding factors.

\section{Materials and Methods}

\section{Study population and questionnaire assessment}

This study is a cross-sectional study using a large self-motivated health screening cohort at the National Cancer Center, Korea. We included participants who underwent a comprehensive screening program including colonoscopy and completed questionnaires from June 2007 to December 2007. We excluded participants who had colorectal cancer, previous colorectal surgery, inflammatory disease of the colon, and abnormal results of thyroid function tests.

The enrolled subjects were racially homogeneous Koreans. Personal data (age, sex, alcohol consumption, smoking status, personal medical history, gastrointestinal symptoms, job, and socioeconomic status) were collected before endoscopy. Smoking and alcohol consumption status was classified as current (daily or occasionally) or non-current. Frequent alcohol consumption was defined as 4 or more drinks per week. The degree of subjective physical and psychological stress was evaluated using a visual analogue scale with responses ranging from 0 (none) to 10 (extreme); we defined stress as mild for responses of 0 to 2 , moderate for 3 to 6 , and severe for 7 to 10 .

IBS was diagnosed according to Rome III criteria, ${ }^{7}$ which have been validated. Recurrent abdominal pain or discomfort at least 3 days per month in the last 3 months associated with two or more of the following with onset at least 6 months before diagnosis: (a) improvement with defecation, (b) onset associated with a change in the frequency of stools, and (c) onset associated with a change in the form of stools.

Weight and height measurement was automated (X-SCAN PLUS II, Jawon Medical Co., Kyungsan City, Korea), and body mass index (BMI) was calculated as weight divided by height squared $\left(\mathrm{kg} / \mathrm{m}^{2}\right){ }^{8}$ Waist circumference was measured at the midpoint between the lower borders of the rib cage.

\section{Colonoscopy}

The day before colonoscopy, participants ingested $45 \mathrm{~mL}$ aqueous Fleet Phospho-soda (Fleet Company, Inc., Lynchburg, VA, USA) in $240 \mathrm{~mL}$ water and ingested $10 \mathrm{mg}$ bisacodyl tablets followed by $1,500 \mathrm{~mL}$ water at $7 \mathrm{pm}$. They ingested another 45 $\mathrm{mL}$ aqueous Fleet Phospho-soda in $240 \mathrm{~mL}$ water followed by $1,500 \mathrm{~mL}$ water at $10 \mathrm{pm}$. We performed the colonoscopy with a colonoscope (Q260AL, Olympus Optical Co., Ltd., Tokyo, Japan), recording the location and size of all polypoid and sessile lesions. Small polyps, less than $1 \mathrm{~cm}$ in diameter, were removed by snare polypectomy or hot biopsy during first-look colonoscopic examination, and large polyps including cancers were treated electively by endoscopic mucosal resection or surgical operation. All polyps or cancers removed endoscopically or surgically were fixed in formaldehyde and sent to the pathologic laboratory for routine histologic examination. The histological evaluation was made according to World Health Organization (WHO) criteria.

All of the endoscopic examinations were performed by experienced endoscopists blinded to the results of the questionnaires. Informed consent for sedated endoscopy and use of personal data for research purposes was obtained from participants before endoscopy.

\section{Statistical methods}

Pearson chi-square test or independent $t$ test was employed to assess the difference in risk factors between the two groups (presence and absence of IBS). Risk factors for IBS were estimated with odds ratios (OR) and 95\% confidence intervals (CI) using logistic regression analysis. Significant risk factors revealed in univariate analysis were subjected to multivariate logistic regression analysis. We used STATA software (version 10, College Station, TX, USA) for our analyses. All statistical tests were two-sided, and $\mathrm{p}<0.05$ was considered statistically significant. 


\section{Results}

\section{Characteristics of participants}

Of 5,605 participants, 4,296 subjects met the study inclusion criteria from June 2007 to December 2007. We excluded subjects who did not undergo colonoscopy $(\mathrm{n}=1,286)$, those

Table 1. Baseline Characteristics of Participants in Health Screening Program

\begin{tabular}{lccc}
\hline & $\begin{array}{c}\text { Total } \\
\text { subjects } \\
(\mathrm{n}=5,605)\end{array}$ & $\begin{array}{c}\text { Eligible } \\
\text { subjects } \\
(\mathrm{n}=4,296)\end{array}$ & $\begin{array}{c}\text { Excluded } \\
\text { subjects } \\
(\mathrm{n}=1,309)\end{array}$ \\
\hline Male sex & $3,140(56)$ & $2,497(58)$ & $643(49)$ \\
Age, years & $50.6 \pm 9.6$ & $50.6 \pm 9.7$ & $50.6 \pm 9.7$ \\
Body mass index, kg/m ${ }^{2}$ & $23.8 \pm 2.9$ & $23.8 \pm 2.9$ & $23.8 \pm 2.8$ \\
Current alcohol consumption & $3,621(65)$ & $2,821(66)$ & $800(61)$ \\
Current smoking & $1,506(28)$ & $1,255(29)$ & $281(21)$ \\
Hypertension & $955(17)$ & $746(17)$ & $209(16)$ \\
Diabetes & $324(6)$ & $261(6)$ & $63(5)$ \\
Depression & $61(1)$ & $44(1)$ & $17(1)$ \\
IBS by ROME III criteria & $461(8)$ & $393(9)$ & $68(5)$
\end{tabular}

IBS, irritable bowel syndrome.

Data are presented as mean $\pm \mathrm{SD}$ or number (percent).

Table 2. Risk Factors for Irritable Bowel Syndrome in the Final Study Sample

\begin{tabular}{|c|c|c|c|}
\hline & $\begin{array}{c}\text { Absence } \\
{\text { of } \text { IBS }^{\mathrm{a}}} \\
(\mathrm{n}=3,903)\end{array}$ & $\begin{array}{c}\text { Presence } \\
\text { of IBS } \\
(n=393)\end{array}$ & $\mathrm{p}$-value \\
\hline Age, years & $50.9 \pm 9.7$ & $47.7 \pm 8.8$ & $<0.001$ \\
\hline Male sex & $2,273(58)$ & $224(57)$ & 0.64 \\
\hline \multicolumn{4}{|l|}{ Habits or disease } \\
\hline Current smoking & $1,108(28)$ & $147(37)$ & 0.001 \\
\hline Current alcohol consumption & $2,541(66)$ & $280(71)$ & 0.04 \\
\hline Frequent alcohol consumption & $1,099(28)$ & $144(37)$ & 0.009 \\
\hline Hypertension & $699(18)$ & $47(12)$ & 0.002 \\
\hline Diabetes & $241(6)$ & $20(5)$ & 0.34 \\
\hline Depression & $34(1)$ & $3(4)$ & 0.02 \\
\hline \multicolumn{4}{|l|}{ Obesity indices } \\
\hline Body mass index, $\mathrm{kg} / \mathrm{m}^{2}$ & $23.8 \pm 2.9$ & $23.7 \pm 3.0$ & 0.64 \\
\hline Waist circumference, $\mathrm{cm}$ & $84.7 \pm 8.5$ & $84.2 \pm 8.5$ & 0.24 \\
\hline \multicolumn{4}{|l|}{ Degree of stress } \\
\hline Physical stress, in the last year & $3.7 \pm 2.5$ & $4.1 \pm 2.4$ & 0.001 \\
\hline $\begin{array}{l}\text { Psychological stress, } \\
\text { in the last year }\end{array}$ & $4.9 \pm 2.5$ & $5.6 \pm 2.3$ & 0.001 \\
\hline
\end{tabular}

${ }^{a}$ IBS denotes irritable bowel syndrome by ROME III criteria, ${ }^{b}$ psychological and physical stress was measured by visual analogue scale (0-10).

Data are presented as mean $\pm \mathrm{SD}$ or number (percent). with colorectal cancer $(\mathrm{n}=16)$, previous colorectal surgery $(\mathrm{n}=$ $1)$, inflammatory disease of the colon $(n=1)$, and abnormal results of thyroid function tests $(\mathrm{n}=6)$. The prevalence of IBS was $8.2 \%(461 / 5,605)$ in total population and $9.1 \%(393 / 4,296)$ in final eligible subjects.

Distributions of age, body mass index, life style factors, hypertension, diabetes mellitus, and depression were not different between total subjects and eligible subjects (Table 1). But prevalence of IBS was more common in eligible subjects comparing with excluded persons $(\mathrm{p}=0.001)$ (Table 1$)$.

\section{Risk factors for irritable bowel syndrome}

IBS had a positive association with current smoking, frequent alcohol consumption, younger age, psychological and physical stress, and absence of hypertension, but it had no association with sex, BMI, waist circumference, and diabetes mellitus (Table 2). Frequent alcohol consumption and current smoking had a strong positive association with psychological stress (data not shown, both $\mathrm{p}<0.001$ ), but not with physical stress.

In multivariate analysis, psychological stress, female sex,

Table 3. Risk Factors for Irritable Bowel Syndrome by Multivariate Analysis

\begin{tabular}{|c|c|c|}
\hline & \multicolumn{2}{|c|}{ IBS by ROME III criteria } \\
\hline & $\mathrm{OR}^{\mathrm{a}}(95 \% \mathrm{CI})$ & p-value \\
\hline Female sex & $1.33(1.00-1.79)$ & 0.05 \\
\hline \multicolumn{3}{|l|}{ Age group } \\
\hline 40.0 years & 1 (Reference) & \\
\hline $40.0-49.9$ years & $0.95(0.68-1.33)$ & 0.78 \\
\hline $50.0-59.9$ years & $0.79(0.54-1.15)$ & 0.22 \\
\hline$\geq 60$ years & $0.51(0.30-0.86)$ & 0.01 \\
\hline Current smoking & $1.31(1.00-1.71)$ & 0.05 \\
\hline Current frequent alcohol consumption & $1.25(0.95-1.65)$ & 0.11 \\
\hline Hypertension & $1.18(0.87-1.59)$ & 0.29 \\
\hline Depression & $0.31(0.04-2.28)$ & 0.25 \\
\hline \multicolumn{3}{|l|}{ Psychological stress, in the past year ${ }^{\mathrm{b}}$} \\
\hline $0-2$ & 1 (Reference) & \\
\hline $3-6$ & $1.52(1.00-2.33)$ & 0.05 \\
\hline $7-10$ & $1.87(1.18-2.99)$ & 0.008 \\
\hline \multicolumn{3}{|l|}{ Physical stress, in the past year ${ }^{\mathrm{b}}$} \\
\hline $0-2$ & 1 (Reference) & \\
\hline $3-6$ & $1.15(0.84-1.56)$ & 0.39 \\
\hline $7-10$ & $1.43(0.92-2.22)$ & 0.11 \\
\hline
\end{tabular}

adjusted for age, sex, body mass index, smoking status, alcohol consumption status, psychological stress status, physical stress status, use of antidepressants, and use of sedatives, ${ }^{\mathrm{b}}$ psychological and physical stress was measured by visual analogue scale; $0-2$ is mild, 3-6 is moderate, and 7-10 is severe stress. $\mathrm{CI}$, confidence interval; IBS, irritable bowel syndrome; OR, odds ratio. 
younger age, and current smoking had a positive association with IBS (Table 3). If psychological and physical stress were separately considered, the prevalence of IBS increased with increasing psychological and physical stress (both $\mathrm{p}$ for trend $<0.001$ ). If they were considered simultaneously, IBS increased with increasing psychological stress (adjusted $\mathrm{p}$ for trend $=0.005$ ); adjusted OR for IBS was 1.52 (95\% CI, 1.00-2.33) for moderate stress and 1.87 (95\% CI, 1.18-2.99) for severe stress, compared with mild stress. However, IBS had no association with physical stress. The prevalence of IBS increased with decreasing age (adjusted $\mathrm{p}$ for trend $<0.001$ ); adjusted OR for IBS was 0.95 (95\% CI, 0.68-1.33) for age of 40.0 to 49.9 years; 0.79 (95\% CI, 0.54-1.15) for age of 50.0 to 59.9 years; and 0.51 (95\% CI, $0.30-0.86$ ) for age of 60 years or more, compared with age less than 40 years. Alcohol consumption status and hypertension had no association with IBS in multivariate analysis.

\section{Discussion}

We found that the prevalence of IBS was $8.2 \%$ in the total group of participants and $9.1 \%$ in the final study sample, after organic diseases were excluded. A higher prevalence in the final study sample compared with the total population might be explained by the following. Whereas persons who had lower gastrointestinal symptoms such as abdominal discomfort or pain were more likely to undergo colonoscopy, persons who had no gastrointestinal symptoms were less likely to undergo colonoscopy, and thus, they were excluded. In population-based studies, the prevalence of IBS by ROME II or III criteria ranged from $2.2 \%$ to $9.6 \%$ in Korea. $^{4-6}$ In this study, the prevalence of IBS by ROME III criteria was similar to that of previous studies. ${ }^{4,5}$ The prevalence of IBS by ROME II or III criteria is approximately $10 \%$ in Western populations. ${ }^{2,3}$ In other studies, the prevalence of IBS was obtained by using validated postal questionnaires or telephone interviews. However, organic diseases should be excluded to estimate the prevalence more exactly. We evaluated the prevalence of and risk factors for IBS after excluding organic diseases in this study.

IBS was weakly associated with female sex in this study. Although previous population-based studies from Korea showed a similar prevalence of IBS in both sexes, ${ }^{4-6}$ many studies from Western populations have shown female predominance., ${ }^{2,9,10}$ Current smoking and frequent alcohol consumption had a strong positive association with IBS in univariate analysis; however, in multivariate analysis, IBS was weakly associated with current smoking and not associated with frequent alcohol consumption. In this study, frequent alcohol consumption and current smoking had a strong positive association with psychological stress, which was strongly associated with IBS, but not with physical stress. Therefore, the effect of frequent alcohol consumption on IBS might be related to psychological stress, rather than drinking itself. Previous studies suggested an association between smoking and colonic dysmotility. ${ }^{11,12}$ Smokers have a significantly longer total colon transit time than nonsmokers, ${ }^{11}$ but short-term application of nicotine results in decreased total colon transit time, which is due to accelerated transit in the rectosigmoid colon. ${ }^{12}$

In this study, when psychological and physical stress was separately considered, the prevalence of IBS increased with both psychological and physical stress. If they were considered simultaneously, however, IBS increased with increasing psychological stress, but it had no association with physical stress. People with IBS have increased psychological distress ${ }^{13}$ compared with people who do not have IBS, most commonly depressed, anxious, or hypochondriacal. ${ }^{14-18}$ Although the results of previous studies suggested that this proportion was increased in secondary and tertiary care, the results of more recent, large, population-based studies suggested that patients with IBS in the community also have increased psychological distress ${ }^{14,19,20}$ compared with people who do not have IBS. A previous study suggested that acute stress altered gut-specific efferent autonomic innervations, and normalization was delayed in patients with IBS. ${ }^{21}$ Actually, experimentally induced anxiety altered gastric sensorimotor function, ${ }^{22}$ and patients with IBS showed enhanced modulation of visceral perception by auditory stress. ${ }^{23}$

The prevalence of IBS increased with decreasing age in this study, with a decrease of about $50 \%$ in participants of age more than 60 years, compared with participants of age less than 40 years. The inverse relationship between IBS and age has been suggested in previous studies from Korea, even if they did not show a statistical significance for the association between IBS and age. ${ }^{5,6}$ Previous studies from Western populations have also suggested the association between IBS and young age. ${ }^{2,9,19}$

This study has several strengths. First, we excluded organic bowel disease by using the results of colonoscopy and abnormal laboratory tests. Second, the data were of high quality. Colonoscopic examinations were performed by gastrointestinal specialists, and anthropometric parameters were measured directly instead of by questionnaire. The third strength was the large size of the study, which allowed us to evaluate subpopulations and their interactions after adjusting for many confounding factors. 
This study also had several limitations. First, the population was a self-motivated screening cohort. The IBS patients with severe symptoms may be evaluated as outpatients, so this study may underrepresent severely symptomatic IBS patients and the prevalence of IBS may be underestimated. However, whereas persons who had lower gastrointestinal symptoms were more likely to undergo colonoscopy, persons who had no gastrointestinal symptoms were less likely to undergo colonoscopy, and thus, the prevalence in the eligible subjects was higher than in the total population. Finally, the prevalence of IBS in this study is similar to the prevalence of IBS in population-based studies using telephone interview surveys. ${ }^{4,5}$ Because a population based-study using colonoscopy may not be realistic, our study using a screening cohort without serious underlying diseases may be an alternative. Second, degrees of psychological and physical stress were evaluated by the scores reported by participants subjectively using a visual analogue scale, not using validated questionnaires. Although there are many methods to assess psychosocial factors, there is no standardized method. Therefore, visual analogue scales may be alternative tools for assessing psychological and physical stress.

In conclusion, the prevalence of IBS is $9.1 \%$ in participants in a health screening program after organic diseases were excluded, and IBS had a positive association with psychological stress, female sex, younger age, and current smoking.

\section{References}

1. Russo MW, Gaynes BN, Drossman DA. A national survey of practice patterns of gastroenterologists with comparison to the past two decades. J Clin Gastroenterol 1999;29:339-343.

2. Andrews EB, Eaton SC, Hollis KA, et al. Prevalence and demographics of irritable bowel syndrome: results from a large web-based survey. Aliment Pharmacol Ther 2005;22:935-942.

3. Spiller R, Aziz Q, Creed F, et al. Guidelines on the irritable bowel syndrome: mechanisms and practical management. Gut 2007;56: 1770-1798.

4. Lee SY, Lee KJ, Kim SJ, Cho SW. Prevalence and risk factors for overlaps between gastroesophageal reflux disease, dyspepsia, and irritable bowel syndrome: a population-based study. Digestion 2009; 79:196-201.

5. Han SH, Lee OY, Bae SC, et al. Prevalence of irritable bowel syndrome in Korea: population-based survey using the Rome II criteria. J Gastroenterol Hepatol 2006;21:1687-1692.

6. Jeong JJ, Choi MG, Cho YS, et al. Chronic gastrointestinal symptoms and quality of life in the Korean population. World J Gastroenterol 2008;14:6388-6394.

7. Longstreth GF, Thompson WG, Chey WD, Houghton LA,
Mearin F, Spiller RC. Functional bowel disorders. Gastroenterology 2006;130:1480-1491.

8. Willett WC, Dietz WH, Colditz GA. Guidelines for healthy weight. N Engl J Med 1999;341:427-434.

9. Gomez Alvarez DF, Morales Vargas JG, Rojas Medina LM, Mujica Oviedo SC, Camacho Lopez PA, Rueda Jaimes GE. Prevalence of irritable bowel syndrome and associated factors according to the Rome III diagnostic criteria in a general population in Colombia. Gastroenterol Hepatol 2009;32:395-400.

10. Katsinelos P, Lazaraki G, Kountouras J, et al. Prevalence, bowel habit subtypes and medical care-seeking behaviour of patients with irritable bowel syndrome in Northern Greece. Eur J Gastroenterol Hepatol 2009;21:183-189.

11. Meier R, Beglinger C, Dederding JP, et al. Influence of age, gender, hormonal status, and smoking habits on colonic transit time. Neurogastroenterol Motil 1995;7:235-238.

12. Rausch T, Beglinger C, Alam N, Gyr K, Meier R. Effect of transdermal application of nicotine on colonic transit in healthy nonsmoking volunteers. Neurogastroenterol Motil 1998;10:263-270.

13. Whitehead WE, Palsson O, Jones KR. Systematic review of the comorbidity of irritable bowel syndrome with other disorders: what are the causes and implications? Gastroenterology 2002;122:1140-1156.

14. Choung RS, Locke GR 3rd, Zinsmeister AR, Schleck CD, Talley NJ. Psychosocial distress and somatic symptoms in community subjects with irritable bowel syndrome: a psychological component is the rule. Am J Gastroenterol 2009;104:1772-1779.

15. Sykes MA, Blanchard EB, Lackner J, Keefer L, Krasner S. Psychopathology in irritable bowel syndrome: support for a psychophysiological model. J Behav Med 2003;26:361-372.

16. Bennett EJ, Piesse C, Palmer K, Badcock CA, Tennant CC, Kellow JE. Functional gastrointestinal disorders: psychological, social, and somatic features. Gut 1998;42:414-420.

17. Drossman DA, Camilleri M, Mayer EA, Whitehead WE. AGA technical review on irritable bowel syndrome. Gastroenterology 2002;123:2108-2131.

18. Gros DF, Antony MM, McCabe RE, Swinson RP. Frequency and severity of the symptoms of irritable bowel syndrome across the anxiety disorders and depression. J Anxiety Disord 2009;23:290-296.

19. Locke GR 3rd, Yawn BP, Wollan PC, Melton LJ 3rd, Lydick E, Talley NJ. Incidence of a clinical diagnosis of the irritable bowel syndrome in a United States population. Aliment Pharmacol Ther 2004; 19:1025-1031.

20. Pan G, Lu S, Ke M, Han S, Guo H, Fang X. Epidemiologic study of the irritable bowel syndrome in Beijing: stratified randomized study by cluster sampling. Chin Med J (Engl) 2000;113:35-39.

21. Murray CD, Flynn J, Ratcliffe L, Jacyna MR, Kamm MA, Emmanuel AV. Effect of acute physical and psychological stress on gut autonomic innervation in irritable bowel syndrome. Gastroenterology 2004;127:1695-1703.

22. Geeraerts B, Vandenberghe J, Van Oudenhove L, et al. Influence of experimentally induced anxiety on gastric sensorimotor function in humans. Gastroenterology 2005;129:1437-1444.

23. Dickhaus B, Mayer EA, Firooz N, et al. Irritable bowel syndrome patients show enhanced modulation of visceral perception by auditory stress. Am J Gastroenterol 2003;98:135-143. 